\title{
Nighttime eating and breast cancer among Chinese women in Hong Kong
}

\author{
Mengjie Li ${ }^{1+}$, Lap Ah Tse ${ }^{1 *+}$, Wing-cheong Chan ${ }^{2}$, Chi-hei Kwok ${ }^{3}$, Siu-lan Leung ${ }^{4}$, Cherry Wu ${ }^{5}$, Wai-cho Yu ${ }^{6}$, \\ Priscilla Ming-yi Lee ${ }^{1}$, Koon-ho Tsang ${ }^{7}$, Sze-hong Law ${ }^{8}$, Roel Vermeulen ${ }^{9}$, Fangyi Gu ${ }^{10}$, Neil E. Caporaso ${ }^{10}$, \\ Ignatius Tak-sun Yu', Feng Wang ${ }^{1}$ and Xiaohong Rose Yang ${ }^{10}$
}

\begin{abstract}
Background: A novel line of research suggests that eating at nighttime may have several metabolic consequences that are highly relevant to breast cancer. We investigated the association between nighttime eating habits after 10 p.m. and breast cancer in Hong Kong women.

Methods: A hospital-based case-control study was conducted during 2012-2015. A total of 922 patients with incident breast cancer (cases) and 913 hospital controls were recruited and interviewed using a standard questionnaire including information on eating behavior during both daytime and nighttime. We collected the timing, duration, types and frequencies of food intake of eating at nighttime. Odds ratios (ORs) for the risk of breast cancer in relation to nighttime eating-related variables were calculated by unconditional multivariable logistic regression.

Results: Eating at night after 10 pm was significantly associated with breast cancer with an adjusted OR of 1.50 (95\% confidence interval $(\mathrm{Cl}) 1.06-2.12, P=0.02)$, and the associations were stronger in women who had the longest duration of nighttime eating ( $\geq 20$ years) (adjusted $\mathrm{OR}=2.28(95 \% \mathrm{Cl} 1.13-4.61, P=0.02)$ and who ate late (midnight to 2 a.m.) (adjusted $\mathrm{OR}=2.73,95 \% \mathrm{Cl} 1.01-6.99, P=0.04$ ). Interestingly, nighttime eating was only associated with breast cancer among women who consumed staple foods ( $\mathrm{OR}=2.16,95 \% \mathrm{Cl} 1.42-3.29, P<0.001)$ but not those who ate vegetables or fruits as nighttime meals. The significant association between nighttime eating and breast cancer was observed among women with body mass index $(\mathrm{BMI})<25(\mathrm{OR}=2.29$, 95\% Cl 1.48-3.52, $P<0.001)$ but not among women with $\mathrm{BMI} \geq 25$.
\end{abstract}

Conclusions: Results from this study suggest a possible association between nighttime eating behavior and breast cancer. These findings need to be confirmed by independent large studies.

Keywords: Nighttime eating behavior, Dietary factors, Breast cancer

\section{Background}

Breast cancer is the most common cancer among women worldwide including women in Hong Kong [1, 2]. Although the age-standardized incidence of female breast cancer in Hong Kong is still lower compared to Northern America and Europe, it has been increasing sharply in recent decades [1]. Such an accelerating rate among Hong Kong women has been mostly attributed to changes in

\footnotetext{
*Correspondence: shelly@cuhk.edu.hk

Mengjie Li and Lap Ah Tse are co-first author

'Equal contributors

${ }^{1} J C$ School of Public Health and Primary Care, the Chinese University of Hong Kong, Hong Kong SAR, China

Full list of author information is available at the end of the article
}

environmental exposure, particularly the adoption of a westernized lifestyle.

Night-eating behavior has become more common in recent years [3]. Evidence from experimental studies showed that rats fed in conflict with their natural nocturnal schedule gained weight despite no change in their diet, whereas there was no weight gain observed in the control group in which rats were fed at the normal time [4]. Epidemiologic studies have provided supportive evidence that food intake in the evening, especially closer to sleep, is more likely to lead to obesity than food consumption at other times of a day $[5,6]$.

Nighttime eating characterized by a circadian delay in daily food intake has been associated with alterations in 
neuroendocrine functions, including food regulatory proteins such as leptin, ghrelin and insulin, and circadian melatonin and cortisol hormones [7-9]. Food intake also functions as an important Zeitgeber (external cue that function to entrain biological rhythms) for peripheral clocks that orchestrate synchrony with brain clocks following the normal day-night cycle $[10,11]$. Eating outside of the orchestrated synchronization has been shown to result in a phase shift and misalignment of normal daily circadian oscillations in rodents, showing a subsequent alteration of metabolic hormone concentrations, which may lead to obesity-related diseases such as cancer $[12,13]$.

Data on the link between night-eating behavior and breast cancer risk are sparse, other than a few experimental studies. Results from the USA study, the National Health and Nutrition Examination Survey (NHANES) showed that an increase in nighttime fasting duration was associated with improved glycemic regulation, which may relate to a reduced risk of breast cancer [14]. The goal of this study was to evaluate the association between night-eating behavior and female breast cancer risk in a breast cancer case-control study that included a comprehensive collection of risk factor data.

\section{Methods}

Details of the study population have been previously described $[15,16]$. Briefly, all participants were recruited from three local hospitals in Hong Kong between August 2012 and March 2015. The inclusion criteria for case participants were: (1) female, aged 20-84 years; (2) incident, histologically confirmed primary breast cancer (International Classification of Disease, Tenth Revision, code 50) diagnosed no more than 3 months prior to the recruitment interview; and (3) of Chinese ethnicity and residing in Hong Kong for at least 5 years. Patients were excluded if they were: (1) too young ( $<20$ years old) or too old ( $\geq 85$ years old); (2) patients who had been diagnosed more than 3 months prior to the date of interview or patients with recurrent breast cancer after initial treatment; and (3) had a history of cancer at any site before breast cancer diagnosis.

The inclusion criteria for control participants were: (1) Chinese women aged 20-84 years old; (2) no history of cancer; (3) admission to the same hospital during the same time period as the case participants; (4) frequencymatched by age ( 5 -year age interval) to case participants; and (5) residents of Hong Kong for at least 5 years. Controls were excluded if they had physician-diagnosed cancer at any site. For our controls we selected patients who had a broad spectrum of diagnoses (such as diseases of the circulatory, genitourinary or nervous system) that were unrelated to breast cancer, to reduce or cap any possible bias [17, 18]. The current report consisted of 922 case participants and 913 controls. The study protocol was approved by both the Joint Chinese University of Hong Kong-New Territories East Cluster Clinical Research Ethics Committees and the Kowloon West Cluster. Written informed consent was obtained from both case participants and controls prior to the interview.

Face-to-face interviews were conducted with both case participants and controls, by trained interviewers using a standardized questionnaire. In addition to diet, other major variables included sociodemographic characteristics, smoking and alcohol drinking, reproductive factors, family cancer history, physical activity, sleeping habits and occupational history including shift work. Anthropometric risk factors were also recorded; height and weight were self-reported, whereas waist, hip circumference and subcutaneous fat thickness were measured by our interviewers using standard measurement tools. Details of recreational physical activities, including type (walking, hiking, running, swimming, ball games, QiGong or others), frequency and duration of each physical activity were recorded. In addition, information on commute including transportation methods and total time spent were also recorded in our questionnaire. Shift work was recorded and defined as "ever worked rotating shifts or night shift (from midnight to 5 a.m.) more than once a month for more than 1 year". We also collected detailed data on nightshift work including type of shiftwork, frequency, duration, cumulative night shifts, and rotating schedules. Sleeping habits, including sleeping duration and quality in the last 5 years, were also collected in the questionnaire.

We assessed each participant's overall dietary habits and supplement intakes within 5 years prior to the interview, using a reduced version of the Block food frequency questionnaire (FFQ) of National Cancer Institute (NCI) with a slight modification [19]. If the dietary habits had changed substantially during the past 5 years, the habits preceding the changes were used for analysis. Participants were asked about their dietary habits related to the frequency of consuming cereal (wheat, rice), coarse grain (e.g. maize, sorghum, millet), fresh vegetables including both green vegetables (e.g. cabbage, spinach, broccoli) and orange vegetables (e.g. carrot, tomato), fresh meat, fresh fruits, preserved vegetables, preserved meat, deep-fried foods, dairy products, soy products, tea and coffee. Daily dietary supplement intakes (e.g. vitamins, beta-carotene, calcium, etc.) were also recorded.

As nighttime food intake was not included in the NCI questionnaire, we developed specific questions to collect data on nighttime eating behavior. In order to avoid "double count", we collected details of the type of food, timing of eating and duration of nighttime eating, 
instead of food frequency, which was already collected in the FFQ. Information was collected on nighttime eating and working history. For those who reported to have worked in one or more full-time jobs, a complete work history was recorded including night work/shift work status and nighttime eating behavior. Nighttime eating was defined as habitual food intake after 10 p.m. at least one time per week for more than one year. Among women who reported a history of nighttime eating, only $15 \%$ ate at nighttime less than once a week. Similar results were observed in the sensitivity analysis removing these women and therefore we used nighttime eating once or more per week as the cutoff point. Type of food, timing of eating (10 p.m.-12 a.m., 12 a.m.-2 a.m., 2 a.m. -4 a.m.) and duration (years) were recorded for those who reported having habitual nighttime eating. Meanwhile, for those who have never had a full-time job, nighttime eating habits within the most recent 5 -year period and details of the frequency of nighttime eating and the food consumed were recorded. Detailed exposure assessment questions about nighttime eating can be found in Additional file 1.

Nighttime food intake was classified into two categories, staple foods and snacks, by meal size and type of food. Staple foods referred to a regular meal, which often contained one type of food that was rich in carbohydrate (e.g. wheat, rice), in addition to variable vegetable or meat content; snacks referred to a portion of food smaller than a regular meal, often containing one or more items such as nuts, dairy products, bakery food, desserts or chips. Those who reported eating multiple food items including both staple foods and snacks were categorized as staple-food eaters. Within each category, food items were further classified into several different categories: noodles (including wheat noodles, rice noodles, instant noodles and pasta), rice (steamed rice and congee), baked goods (breads, cakes, biscuits, etc.), vegetables (as the main ingredient), and meat (as a primary ingredient).

The independent $t$ test and chi-square test were performed to test the differences between case participants and controls in sociodemographic factors for continuous and categorical data, respectively. Multivariable logistic regression was used to calculate the odds ratio (OR) and 95\% confidence interval (95\% CIs) for the association between variables related to nighttime eating and breast cancer risk, with adjustment for potential confounding factors. To select potential confounders to be included in the multivariable model, we first conducted univariate analysis with adjustment for age (age at diagnosis in case participants and age at interview in controls) and a single risk factor only.

All known or suspected breast cancer risk factors ascertained, including detailed shift work, were analyzed in the univariate analysis, and those with $P$ values $<0.05$ were further included in the final multivariable logistic regression models. The factors assessed included sociodemographic characteristics, reproductive factors, family history of cancer, history of benign breast disease and other medical conditions, smoking and alcohol consumption, anthropometric factors, physical activity, lifetime work history and shift work status, sleep pattern and exposure to light at night.

Three multivariable regression models were presented separately, adjusted for: (1) age only; (2) age and all breast cancer risk factors with $P<0.05$ in the univariate analysis; and (3) model (1) plus total dietary intake variables that were significantly associated with breast cancer. To evaluate the potential effect modification, we formally tested the interactions between nighttime eating and menopausal status, estrogen receptor (ER) status and body mass index (BMI) by including interaction terms in the regression models involving all subjects. We also conducted stratified analyses of these variables.

We performed a number of sensitivity analyses including analysis (1) excluding controls with digestive system disease (which may be associated with dietary intake or nighttime eating) to probe the potential bias caused by medical diseases in hospital-based controls; (2) analyzing a specific group of patients who underwent breast biopsy and were initially considered as patients with breast cancer but were eventually confirmed to be non-cancer case participants; and (3) removing women who reported particular frequencies of nighttime eating to find an appropriate cutoff point for nighttime eating behavior.

\section{Results}

The basic characteristics of case participants with breast cancer and the distribution of selected breast cancer risk factors are presented in Table 1. The mean age at breast cancer diagnosis was $56.0 \pm 11.8$ years. Compared with controls, case participants were significantly younger at menarche and older at first birth, were more likely to have family history of cancer in first-degree relatives, were more likely to be obese $(\mathrm{BMI}>25)$ and were less likely to have ever been employed in shift work. Other variables including menopausal status, educational attainment, the use of oral contraceptives or hormone replacement therapy, parity, smoking and alcohol drinking and sleeping pattern did not vary significantly by case-control status.

The frequency of total food consumption among case participants and controls in the 5 years prior to the study is shown in Additional file 2: Table S1. After adjusting for known breast cancer risk factors including age at interview, age at menarche, age at first birth, BMI, family history of any cancer among first-degree relatives, shift work and all major food 
Table 1 Distribution of basic characteristics and selected breast cancer risk factors among Hong Kong Chinese women, 2012-15

\begin{tabular}{|c|c|c|}
\hline Variables & $\begin{array}{l}\text { Case participants } \\
(n=922)\end{array}$ & $\begin{array}{l}\text { Controls } \\
(n=913)\end{array}$ \\
\hline Age at interview (years) & $56.0 \pm 11.8$ & $53.7 \pm 11.7$ \\
\hline Age at menarche (years) & $13.6 \pm 2.0$ & $13.8 \pm 2.3$ \\
\hline Age at first birth (years) & $26.4 \pm 4.9$ & $25.6 \pm 4.7$ \\
\hline $\mathrm{BMI}\left(\mathrm{kg} / \mathrm{m}^{2}\right)$ & $23.5 \pm 3.7$ & $23.0 \pm 3.9$ \\
\hline \multicolumn{3}{|l|}{$B M l^{\mathrm{a}}$} \\
\hline Underweight $(<18.5)$ & $44(4.8)$ & $74(8.1)$ \\
\hline Normal (18.5-22.9) & $329(35.7)$ & $350(38.3)$ \\
\hline Overweight (23.0-24.9) & $160(17.4)$ & $157(17.2)$ \\
\hline Obesity I (25-29.9) & $205(22.2)$ & $162(17.7)$ \\
\hline Obesity II ( $\geq 30)$ & $45(4.9)$ & $40(4.4)$ \\
\hline Unknown & $139(15.1)$ & $130(14.2)$ \\
\hline \multicolumn{3}{|c|}{ First-degree family cancer history } \\
\hline Yes & $323(35.0)$ & $246(26.9)$ \\
\hline No & $572(62.0)$ & $652(71.4)$ \\
\hline Unknown & $27(2.9)$ & $15(1.6)$ \\
\hline \multicolumn{3}{|c|}{ Family history of breast cancer } \\
\hline Yes & $70(7.6)$ & $28(3.1)$ \\
\hline No & $825(89.5)$ & $870(95.3)$ \\
\hline Unknown & $27(2.9)$ & $15(1.6)$ \\
\hline \multicolumn{3}{|l|}{ Parity, number of births } \\
\hline 0 & $164(17.8)$ & $154(16.8)$ \\
\hline $1-2$ & $484(52.5)$ & $473(51.8)$ \\
\hline$\geq 3$ & $228(24.7)$ & $269(29.5)$ \\
\hline Unknown & $46(5.0)$ & $17(1.9)$ \\
\hline \multicolumn{3}{|l|}{ Smoking } \\
\hline Ever & $63(6.8)$ & $69(7.6)$ \\
\hline Never & $859(93.2)$ & $844(92.4)$ \\
\hline \multicolumn{3}{|l|}{ Alcohol drinking } \\
\hline Yes & $47(5.1)$ & $41(4.5)$ \\
\hline No & $875(94.9)$ & $872(95.5)$ \\
\hline \multicolumn{3}{|l|}{ Shift work } \\
\hline Yes & $111(12.0)$ & $150(16.4)$ \\
\hline No & 771 (83.6) & $737(80.7)$ \\
\hline Unknown & $40(4.3)$ & $26(2.8)$ \\
\hline \multicolumn{3}{|l|}{ Histological type } \\
\hline Ductal & $809(87.7)$ & \\
\hline Lobular & $30(3.3)$ & \\
\hline Mucinous & $36(3.9)$ & \\
\hline Medullary & $3(0.3)$ & \\
\hline Others & $44(4.8)$ & \\
\hline \multicolumn{3}{|l|}{ Tumor stage } \\
\hline Stage I & 240 (31.8) & \\
\hline
\end{tabular}

Table 1 Distribution of basic characteristics and selected breast cancer risk factors among Hong Kong Chinese women, 2012-15 (Continued)

\begin{tabular}{ll}
\hline Stage II & $298(39.4)$ \\
Stage III & $96(12.7)$ \\
Stage IV & $42(5.6)$ \\
Un-staged & $79(10.5)$ \\
Estrogen receptor status & \\
Positive & $601(76.7)$ \\
Negative & $183(23.3)$ \\
Progesterone receptor status & \\
Positive & $450(59.5)$ \\
Negative & $306(40.5)$ \\
C-erbB2/HER2 & \\
Negative(IHC score 0/1) & $351(45.8)$ \\
Weakly positive (IHC score 2) & $268(35.0)$ \\
Positive (IHC score 3) & $147(19.2)$
\end{tabular}

Values expressed as mean \pm SD or number (percent). Subjects with missing

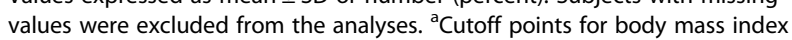
(BMI) recommended by the World Health Organization to classify overweight and obese individuals in Asian populations. HER2 human epidermal growth factor receptor 2, IHC immunohistochemical analysis

categories, case participants with breast cancer tended to have higher consumption of deep-fried food ( $\mathrm{OR}=$ $1.68,95 \%$ CI $1.08-2.59, P=0.02)$ and dairy products (OR $=1.37,95 \%$ CI 1.00-1.87, $P=0.05)$. The intake of other food items did not differ significantly in case participants and controls (Additional file 2: Table S1).

Associations between nighttime eating habits and breast cancer are summarized in Table 2. Nighttime eating was more common among case participants with breast cancer (17.4\%) than among controls (15.2\%). After adjusting for selected confounding factors (including dietary factors), we observed a significant association between risk of breast cancer among case participants who had a habit of nighttime eating compared with those who never ate at night $(\mathrm{OR}=1.50,95 \%$ CI 1.06 $2.12, P=0.02)$. The association was stronger among women who consumed staple foods (adjusted $\mathrm{OR}=2.16$, 95\% CI 1.42-3.29, $P<0.001)$, particularly noodles $(\mathrm{OR}=$ $2.79,95 \%$ CI $1.58-4.94, P<0.001)$ or rice $(\mathrm{OR}=2.58$, $95 \%$ CI 1.42-4.69, $P=0.002$ ). Breast cancer in case participants may be associated with consumption of meat at night time $(\mathrm{OR}=1.73,95 \%$ CI $0.84-3.59, P=0.14)$, but this was not statistically significant. There was no evidence of a relationship between breast cancer and the consumption of vegetables $(\mathrm{OR}=1.14,95 \%$ CI $0.63-2.55$, $P=0.61)$ or fruits $(\mathrm{OR}=1.20,95 \% \mathrm{CI} 0.51-2.83, P=0.68)$ at nighttime.

We further conducted a more detailed analysis of the 894 case participants and 882 control participants who had completed records on duration and timing of 
Table 2 Associations between nighttime eating behavior and breast cancer in Hong Kong Chinese women

\begin{tabular}{|c|c|c|c|c|c|c|}
\hline Variables & $\begin{array}{l}\text { Case participants } \\
(n=922)\end{array}$ & $\begin{array}{l}\text { Controls } \\
(n=913)\end{array}$ & $\begin{array}{l}\mathrm{OR}^{\mathrm{a}} \\
(95 \% \mathrm{Cl})\end{array}$ & $\begin{array}{l}\mathrm{OR}^{\mathrm{b}} \\
(95 \% \mathrm{Cl})\end{array}$ & $\begin{array}{l}\mathrm{OR}^{\mathrm{C}} \\
(95 \% \mathrm{Cl})\end{array}$ & $P$ value \\
\hline \multicolumn{7}{|c|}{ Nighttime eating after 10 p.m. } \\
\hline Never $^{e}$ & $762(82.6)$ & $774(84.8)$ & 1.00 (ref) & 1.00 (ref) & 1.00 (ref) & \\
\hline Ever & $160(17.4)$ & $139(15.2)$ & $1.31(1.02-1.68)$ & $1.51(1.08-2.12)$ & $1.50(1.06-2.12)$ & 0.02 \\
\hline \multicolumn{7}{|l|}{ Meal type } \\
\hline Never $^{\mathrm{e}}$ & $762(82.6)$ & $774(84.8)$ & 1.00 (ref) & 1.00 (ref) & 1.00 (ref) & \\
\hline Staple food & $123(13.3)$ & $86(9.4)$ & $1.65(1.22-2.22)$ & $2.16(1.43-3.28)$ & $2.16(1.42-3.29)$ & $<0.001$ \\
\hline Snacks & $37(4.0)$ & $53(5.8)$ & $0.75(0.48-1.15)$ & $0.75(0.44-1.29)$ & $0.74(0.43-1.27)$ & 0.27 \\
\hline \multicolumn{7}{|l|}{ Food type } \\
\hline Never ${ }^{\mathrm{e}}$ & $762(82.6)$ & $774(84.8)$ & 1.00 (ref) & 1.00 (ref) & 1.00 (ref) & \\
\hline Noodles & $70(7.6)$ & $40(4.4)$ & $1.93(1.29-2.90)$ & $2.78(1.58-4.87)$ & $2.79(1.58-4.94)$ & $<0.001$ \\
\hline Rice & $62(6.7)$ & $37(4.1)$ & $1.90(1.24-2.91)$ & $2.53(1.40-4.47)$ & $2.58(1.42-4.69)$ & 0.002 \\
\hline Baked goods & $30(3.3)$ & $37(4.1)$ & $0.88(0.54-1.44)$ & $1.27(0.71-2.28)$ & $1.19(0.66-2.16)$ & 0.56 \\
\hline Meat & $31(3.4)$ & $23(2.9)$ & $1.48(0.85-2.57)$ & $1.89(0.92-3.88)$ & $1.73(0.84-3.59)$ & 0.14 \\
\hline Vegetable & $24(2.6)$ & $22(2.4)$ & $1.09(0.76-2.11)$ & $1.15(0.67-2.67)$ & $1.14(0.63-2.55)$ & 0.61 \\
\hline Fruit & $15(1.6)$ & $13(1.4)$ & $1.22(0.58-2.59)$ & $1.18(0.51-2.74)$ & $1.20(0.51-2.83)$ & 0.68 \\
\hline
\end{tabular}

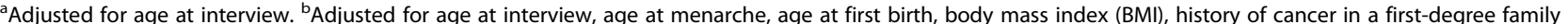
member and shift work. 'Adjusted for age at interview, age at menarche, age at first birth, BMI, history of cancer in a first-degree family member, shift work and other dietary factors (consumption of cereals, deep-fried foods, preserved meats and dairy products). ${ }^{\mathrm{d} P}$ values from model 3 . ${ }^{\mathrm{e}}$ Those who did not have habitual nighttime eating behavior. $P$ values in italics are statistically significant. ref reference

nighttime eating habits (Table 3). Long duration of nighttime eating ( $>20$ years) appeared to have the strongest association with breast cancer status $(\mathrm{OR}=2.28$, 95\% CI 1.13-4.61, $P=0.02$ ). The association with nighttime eating did not seem to vary significantly by the timing of food consumption, although eating between midnight and 2 a.m. had the strongest effect in the multivariable model $(\mathrm{OR}=2.73,95 \% \mathrm{CI} 1.01-6.99, P=0.04)$.
Results of analyses stratified by menopausal status and ER status are presented in Additional files 3 and 4 . Nighttime associations were similar in premenopausal and postmenopausal women overall and in subgroup analyses by meal type (Additional file 3: Table S2). Similar results were also observed among women with ER-positive and ER-negative cancer, with stronger associations seen among women with ER-positive compared

Table 3 Associations between breast cancer and the timing of eating and duration of nighttime eating behavior in Hong Kong Chinese women

\begin{tabular}{|c|c|c|c|c|c|c|}
\hline Variables & $\begin{array}{l}\text { Case participants } \\
(n=894)\end{array}$ & $\begin{array}{l}\text { Controls } \\
(n=882)\end{array}$ & $\begin{array}{l}\mathrm{OR}^{\mathrm{a}} \\
(95 \% \mathrm{Cl})\end{array}$ & $\begin{array}{l}\mathrm{OR}^{\mathrm{b}} \\
(95 \% \mathrm{Cl})\end{array}$ & $\begin{array}{l}\mathrm{OR}^{\mathrm{C}} \\
(95 \% \mathrm{Cl})\end{array}$ & $P$ value \\
\hline \multicolumn{7}{|l|}{ Duration } \\
\hline None & $762(85.2)$ & $774(87.8)$ & 1.00 (ref) & 1.00 (ref) & 1.00 (ref) & \\
\hline$<10$ & $48(5.4)$ & $45(5.1)$ & $1.34(0.87-2.06)$ & $1.76(0.99-3.13)$ & $1.75(0.97-3.14)$ & 0.06 \\
\hline 10-19 & $40(4.5)$ & $42(4.8)$ & $1.05(0.67-1.64)$ & $1.46(0.81-2.63)$ & $1.46(0.80-2.65)$ & 0.22 \\
\hline$\geq 20$ & $44(4.9)$ & $21(2.4)$ & $2.23(1.30-3.82)$ & $2.08(1.05-4.15)$ & $2.28(1.13-4.61)$ & 0.02 \\
\hline \multicolumn{7}{|l|}{ Timing } \\
\hline None & $762(85.2)$ & 774 (87.8) & 1.00 (ref) & 1.00 (ref) & 1.00 (ref) & \\
\hline 10 p.m.-12 a.m. & $78(8.7)$ & $58(6.6)$ & $1.54(1.08-2.21)$ & $1.80(1.11-2.90)$ & $1.84(1.14-2.98)$ & 0.01 \\
\hline 12 a.m.-2 a.m. & $20(2.2)$ & $15(1.7)$ & $1.43(0.72-2.82)$ & $2.50(1.00-6.26)$ & $2.73(1.01-6.99)$ & 0.04 \\
\hline 2 a.m.-4 a.m. & $12(1.3)$ & $12(1.4)$ & $1.08(0.48-2.43)$ & $1.98(0.79-4.97)$ & $1.93(0.76-4.94)$ & 0.17 \\
\hline Irregular ${ }^{\mathrm{e}}$ & $22(2.5)$ & $23(2.6)$ & $1.14(0.62-2.08)$ & $0.99(0.42-2.37)$ & $0.99(0.41-2.40)$ & 0.98 \\
\hline
\end{tabular}

${ }^{a}$ Adjusted for age at interview. ${ }^{b}$ Adjusted for age at interview, age at menarche, age at first birth, body mass index (BMI), history of cancer in a first-degree family member and shift work. 'Adjusted for age at interview, age at menarche, age at first birth, BMI, history of cancer in a first-degree family member, shift work and other dietary factors (consumption of cereals, deep-fried foods, preserved meats and dairy products). ${ }^{\mathrm{d}} P$ value for model 3 . ${ }^{\mathrm{e}}$ No fixed time for nighttime eating. $P$ values in italics are statistically significant. ref reference 
with ER-negative cancer (Additional file 4: Table S3), possibly due to the small number of ER-negative case participants.

Table 4 shows the analyses stratified by BMI (BMI $<25$ and $\mathrm{BMI} \geq 25$ ). The association between nighttime eating and breast cancer was only observed among women with $\mathrm{BMI}<25(\mathrm{OR}=2.29,95 \% \mathrm{CI} 1.48-3.52, P<0.001)$ but not among women with $\mathrm{BMI} \geq 25$ (OR $=0.65,95 \%$ CI $0.36-1.18, P=0.16$ ). A similar pattern was observed in subgroup analyses by meal and food type (Table 4). The interaction between nighttime eating and BMI was statistically significant $(P$ for interaction $=0.01$ particularly for consumption of staple food ( $P$ for interaction $=0.03$ ). Similar results were obtained when a different cutoff $(\mathrm{BMI}=23)$ was used (data not shown).

Similar results were obtained from the sensitivity analysis excluding controls with digestive disease (data not shown). Furthermore, to evaluate the influence of recall or interview bias, we compared the proportion of patients who reported nighttime eating among a group of 131 patients, who were initially suspected of having breast cancer but eventually were confirmed to have benign breast disease, to all controls and observed similar frequencies of nighttime eating $(16.0 \%$ vs. $15.2 \%$, respectively).

\section{Discussion}

In this breast cancer case-control study among Chinese women in Hong Kong, we showed that nighttime eating might be significantly associated with risk of breast cancer, in particular among women with BMI $<25$, who have had nighttime eating habits for more than 20 years and who consume energy-dense foods rich in carbohydrate after 10 p.m. (such as rice or noodles), implicating nighttime eating as a potential new risk factor for breast cancer.

Nighttime eating has long been reported to have a negative impact on health and body composition, with consequences that include weight gain and obesity, which are well-known risk factors for postmenopausal breast cancer [6]. Animal studies and epidemiologic data have provided convincing evidence that consuming a larger proportion of calories later in the day as opposed to earlier in the day is associated weight gain and obesity [5, 20-24]. In particular, obesity is more prevalent among people with night eating syndrome (NES), which is an eating disorder characterized by a delayed circadian pattern of food intake [25]. However, studies on how nighttime eating behavior influences the risk of breast cancer are very limited. Our results are consistent with previous findings based on data from the NHANES and the Women's Healthy Eating and Living study, in which longer nighttime fasting was associated with reduced risk of breast cancer and recurrence of breast cancer [14, 26]. In addition, our findings related to food choice are also in line with previous literature reporting that only the intake of large quantities of high-energy food, and not small low-energy snacks, at night had a negative health impact [27-32].

Table 4 Associations between nighttime eating and breast cancer stratified by BMI

\begin{tabular}{|c|c|c|c|c|c|c|c|}
\hline \multirow[t]{2}{*}{ Variables } & \multicolumn{3}{|l|}{$\mathrm{BMl}<25$} & \multicolumn{3}{|l|}{$\mathrm{BMI} \geq 25$} & \multirow{2}{*}{$\begin{array}{l}\text { Interaction } \\
\text { by BMl } \\
\text { status }\end{array}$} \\
\hline & $\begin{array}{l}\text { Case participants } \\
(n=533)\end{array}$ & $\begin{array}{l}\text { Controls } \\
(n=581)\end{array}$ & OR $(95 \% \mathrm{Cl})^{\mathrm{a}}$ & $\begin{array}{l}\text { Case participants } \\
(n=250)\end{array}$ & $\begin{array}{l}\text { Controls } \\
(n=202)\end{array}$ & OR $(95 \% \mathrm{Cl})^{\mathrm{a}}$ & \\
\hline \multicolumn{8}{|c|}{ Nighttime eating after 10 p.m. } \\
\hline Never & 434 & 502 & 1.00 (ref) & 205 & 158 & 1.00 (ref) & \\
\hline Ever & 99 & 79 & $2.29(1.48-3.52)^{*}$ & 45 & 44 & $0.65(0.36-1.18)$ & 0.01 \\
\hline \multicolumn{8}{|l|}{ Meal type } \\
\hline Never & 434 & 502 & 1.00 (ref) & 205 & 158 & 1.00 (ref) & \\
\hline Staple food & 81 & 51 & $3.30(1.95-5.59)^{*}$ & 34 & 25 & $0.85(0.40-1.79)$ & 0.03 \\
\hline Snacks & 23 & 30 & $1.26(0.62-2.57)$ & 12 & 20 & $0.38(0.16-0.93)^{*}$ & 0.20 \\
\hline \multicolumn{8}{|l|}{ Food type } \\
\hline Never & 434 & 502 & 1.00 (ref) & 205 & 158 & 1.00 (ref) & \\
\hline Noodles & 44 & 26 & $4.07(2.02-8.20)^{*}$ & 20 & 10 & $1.01(0.35-2.95)$ & 0.27 \\
\hline Rice & 39 & 20 & $4.41(2.05-9.49)^{*}$ & 15 & 13 & $0.85(0.30-2.36)$ & 0.09 \\
\hline Baked goods & 21 & 23 & $1.81(0.88-3.73)$ & 8 & 9 & $0.46(0.15-1.38)$ & 0.21 \\
\hline Meat & 20 & 12 & $3.14(1.25-7.88)^{*}$ & 9 & 9 & $0.51(0.14-1.86)$ & 0.12 \\
\hline Vegetable & 14 & 12 & $1.68(0.64-4.38)$ & 10 & 7 & $0.88(0.22-3.57)$ & 0.81 \\
\hline Fruit & 10 & 7 & $2.98(1.02-8.72)^{*}$ & 1 & 6 & $0.13(0.01-1.20)$ & 0.08 \\
\hline
\end{tabular}

${ }^{a}$ Adjusted for age at interview, age at menarche, age at first birth, first-degree family cancer history, shift work and other dietary factors (consumption of cereals, deep-fried foods, preserved meats and dairy products)

*Statistically significant $(P$ value $<0.05)$. For "Interaction by BMI status", $P$ values in italics are statistically significant. BMI body mass index, ref reference 
The mechanisms underlying the association between nighttime eating and risk of breast cancer remains unknown and may be mediated through weight gain and obesity $[5,21-24]$, glucose tolerance and insulin resistance [30, 33, 34], increased systemic inflammation [35], and circadian rhythm disruption caused by food intake [36, 37]. Interestingly, we only observed the association between nighttime eating and breast cancer among slim women, suggesting that the association might be mediated through an obesity-independent mechanism. The strong association between obesity and breast cancer may have masked the association between nighttime eating and breast cancer among obese women. Alternatively, it is also possible that the lack of association among obese women is driven by the underreporting of nighttime food consumption in obese case participants as this has been shown to be a common issue [38, 39]. In fact, case participants with breast cancer were indeed more likely to be obese (27.1\% for case participants vs. $22.1 \%$ for controls) in our study and the potential underreporting would have biased the results toward the null.

Consistent with a recent large meta-analysis [38] and two Chinese studies with a prospective cohort study design $[39,40]$, night shift work was not significantly associated with increased risk of breast cancer in our study, suggesting that the association between nighttime eating and breast cancer was not driven by the night shift work. Circadian disruption caused by nighttime eating may also lead to disturbances in the quantity and quality of sleep [41], which may adversely impact health, including risk of breast cancer [41, 42]. However, studies on associations between sleeping duration, quality or disturbance and breast cancer risk have yielded inconsistent or even conflicting findings [43-49]. In our study, sleeping habits (such as duration and quality) did not differ between case participants and controls. Further, the association between nighttime eating and breast cancer seem to be restricted to specific food types and to lean women, suggesting that the association was not driven by sleep disturbance.

This study provides new insights into nighttime eating habits as potential risk factors for breast cancer. However, we are aware that our study is limited by the hospital case-control design and the small number of subjects, and therefore our findings need to be interpreted with caution. Large prospective studies are needed to confirm these results. Nevertheless, we conducted detailed analyses of nighttime eating variables such as timing, duration, frequency, and type of food consumption, with careful adjustment for known breast cancer risk factors, total dietary habits and night shift work.

We also conducted several sensitivity analyses to assess whether the associations were influenced by recall bias or the potential issue related to self-reported dietary habits among hospital controls. In order to minimize recall bias, we recruited only case participants with incident cancer and tried to introduce this study to participants as a general "women's health" study rather than a cancer study. Analysis of test-re-test reliability was also conducted to check the reproducibility of interview results. Telephone interviews were conducted by the same interviewer at least one month after the first interview with 158 case participants (17.1\%) and 153 controls $(16.8 \%)$. There was good agreement for identification of nighttime eating exposure (consistency rate $=$ $83 \%$; kappa $=0.59,95 \%$ CI $0.35-0.83$ ) between the first and second interviews. In addition, in sensitivity analysis comparing 131 patients, who were initially suspected of having breast cancer but eventually were confirmed to have benign breast disease, to all controls also suggested that recall or interviewer bias may not have seriously influenced our results. Further, dietary habits in hospital controls may differ from those of the general population due to health conditions, consciousness or diseases, particularly among those with diseases of the digestive system. However, previous methodology studies showed that even if a particular segment of the controls has altered diet practices, bias is constrained [18]. In support of this, we recruited hospital controls with a broad range of diagnoses, and the sensitivity analyses indicated that the association between nighttime eating and breast cancer remained significant after excluding control subjects with digestive disease.

Due to the retrospective study design, data on quantities of food intake or total calorie intake were not collected due to difficulty in accurately recalling the amounts of food consumed a long time ago. To address this limitation, we accounted for the overall consumption of different types of food items and BMI in our analyses. Further, we found that the association between nighttime eating and breast cancer was more significant among slim women, suggesting that the association was not driven by excessive calories.

The FFQ is a tool to estimate food and nutrient consumption and has been widely used in investigating the associations between diet and chronic disease [50]. However, the FFQ may be sensitive to the diverse lifestyle, eating habits and dietary preferences in the population concerned [51]. In this study, we used NCI questionnaire to access the dietary intake and a few modifications had been made in relation to dietary habits in the Hong Kong Chinese population. Although this questionnaire have been reported to perform well in many populations [52], the reproducibility and validity of this questionnaire should be conducted among the Hong Kong population in future studies. 


\section{Conclusion}

In conclusion, our findings suggest that nighttime eating was more common among breast cancer case participants compared with control participants. More epidemiological studies, especially with a prospective design and a large number of subjects, are needed to confirm this association and to explore the underlying mechanisms.

\section{Additional files}

Additional file 1: Nighttime eating exposure assessment. (DOCX 13 kb)

Additional file 2: Table S1. Distribution of dietary factors among breast cancer cases and controls in Hong Kong Chinese women, 2012-15. (DOCX $32 \mathrm{~kb}$ )

Additional file 3: Table S2. Associations between nighttime eating and breast cancer stratified by menopausal status. (DOCX 14 kb)

Additional file 4: Table S3. Associations between nighttime eating and breast cancer stratified by ER status. (DOCX 14 kb)

\section{Abbreviations}

BMI: Body mass index; Cl: Confidence interval; ER: Estrogen receptor status; FFQ: Food frequency questionnaire; HER2: Human epidermal growth factor receptor 2; IHC: Immunohistochemical analysis; NCl: National Cancer Institute; NES: Night eating syndrome; NHNES: National Health and Nutrition Examination Survey; OR: Odds ratio

\section{Acknowledgements}

The authors are grateful to Miss Yin-shan Magdalene Leung, Hiu-man Tess Tsoi, Hung-kuen Ivy Hsu and Kit-Ping Apple Kwok for their assistance in recruiting patients and data collection. We would also like to acknowledge Ying-lun Jonathan Chan, Chui-shan Yip and Wing-chi Fung for their contribution to data entry and management.

\section{Funding}

This work was supported by the Research Grants Council of Hong Kong (grant number 474811).

\section{Availability of data and materials}

All data generated or analyzed during this study are included in this published article (and its supplementary information files).

\section{Authors' contributions}

LT and ITY contributed to the conception and design of the study proposal. WC, CK, SL, CW, WY, KT and SL identified the eligible case participants with breast cancer or hospital controls, and helped with the acquisition of written consent. ML and PML conducted interviews and collected epidemiological data from participants. ML and FW collected clinical data from hospital medical records. ML performed data analysis and interpretation, and was a major contributor in writing the manuscript. LT and RY revised the manuscript critically for important intellectual content. RV, FG and NC reviewed the manuscript and provided suggestions for the revision. All authors read and approved the final manuscript.

\section{Competing interests}

The authors declare that they have no competing interests.

\section{Consent for publication}

Not applicable.

\section{Ethics approval and consent to participate}

The study protocol was approved by both the Joint Chinese University of Hong Kong-New Territories East Cluster Clinical Research Ethics Committees and the Kowloon West Cluster. Written informed consent was obtained for both case participants and controls prior to the interview.

\section{Publisher's Note}

Springer Nature remains neutral with regard to jurisdictional claims in published maps and institutional affiliations.

\section{Author details}

${ }^{1} \mathrm{JC}$ School of Public Health and Primary Care, the Chinese University of Hong Kong, Hong Kong SAR, China. ' ${ }^{2}$ epartment of Surgery, North District Hospital, Hong Kong SAR, China. ${ }^{3}$ Department of Oncology, Princess Margaret Hospital, Hong Kong SAR, China. ${ }^{4}$ Department of Surgery, Pamela Youde Nethersole Eastern Hospital, Hong Kong SAR, China. ${ }^{5}$ Department of Pathology, North District Hospital, Hong Kong SAR, China. 'Department of Medicine, Princess Margaret Hospital, Hong Kong SAR, China. ${ }^{7}$ Department of Pathology, Yan Chai Hospital, Hong Kong SAR, China. ${ }^{8}$ Department of Surgery, Yan Chai Hospital, Hong Kong SAR, China. ${ }^{9}$ Institute for Risk Assessment Sciences, Utrecht University, Utrecht, Netherlands. ${ }^{10}$ Genetic Epidemiology Branch, Division of Cancer Epidemiology \& Genetics, National Cancer Institute, National Institutes of Health, Bethesda, USA.

Received: 19 October 2016 Accepted: 1 March 2017

Published online: 17 March 2017

\section{References}

1. GLOBOCAN 2012 v1.0. Cancer incidence and mortality worldwide: IARC CancerBase No. 11 [Internet]. Lyon: International Agency for Research on Cancer [http://globocan.iarc.fr]. Accessed 1 Sept 2016.

2. Hong Kong Cancer Registry, Hospital Authority. Female Breast Cancer in 2014. [http://www3.ha.org.hk/cancereg/pdf/factsheet/2014/breast_2014.pdf]. Accessed 1 Sept 2016.

3. Striegel-Moore RH, Franko DL, Thompson D, Affenito S, Kraemer HC. Night eating: prevalence and demographic correlates. Obesity. 2006;14(1):139-47.

4. Paschos GK, Ibrahim S, Song W-L, Kunieda T, Grant G, Reyes TM, Bradfield CA, Vaughan CH, Eiden M, Masoodi M. Obesity in mice with adipocytespecific deletion of clock component Arntl. Nat Med. 2012;18(12):1768-77.

5. Gluck ME, Venti CA, Salbe AD, Krakoff J. Nighttime eating: commonly observed and related to weight gain in an inpatient food intake study. Am J Clin Nutr. 2008;88(4):900-5

6. Kinsey AW, Ormsbee MJ. The health impact of nighttime eating: old and new perspectives. Nutrients. 2015;7(4):2648-62.

7. Birketvedt GS, Florholmen J, Sundsfjord J, Østerud B, Dinges D, Bilker W, Stunkard A. Behavioral and neuroendocrine characteristics of the nighteating syndrome. JAMA. 1999;282(7):657-63.

8. Goel N, Stunkard AJ, Rogers NL, Van Dongen HP, Allison KC, O'Reardon JP, Ahima RS, Cummings DE, Heo M, Dinges DF. Circadian rhythm profiles in women with night eating syndrome. J Biol Rhythm. 2009;24(1):85-94.

9. Milano W, De Rosa M, Milano L, Capasso A. Night eating syndrome: an overview. J Pharm Pharmacol. 2012:64(1):2-10.

10. Eckel-Mahan K, Sassone-Corsi P. Metabolism and the circadian clock converge. Physiol Rev. 2013;93(1):107-35.

11. Ehlers CL, Frank E, Kupfer DJ. Social zeitgebers and biological rhythms: a unified approach to understanding the etiology of depression. Arch Gen Psychiatry. 1988;45(10):948-52.

12. Hatori M, Vollmers C, Zarrinpar A, DiTacchio L, Bushong EA, Gill S, Leblanc M, Chaix A, Joens M, Fitzpatrick JA. Time-restricted feeding without reducing caloric intake prevents metabolic diseases in mice fed a high-fat diet. Cell Metab. 2012;15(6):848-60

13. Froy $\mathrm{O}$, Miskin R. Effect of feeding regimens on circadian rhythms: implications for aging and longevity. Aging (Albany NY). 2010;2(1):7-27.

14. Marinac CR, Natarajan L, Sears DD, Gallo LC, Hartman SJ, Arredondo E, Patterson RE. Prolonged nightly fasting and breast cancer risk: findings from NHANES (2009-2010). Cancer Epidemiol Biomarkers Prev. 2015:24(5):783-9.

15. Tse LA, Li M, Chan WC, Kwok CH, Leung SL, Wu C, Yu IT, Yu WC, Lao X, Wang $X$, et al. Familial risks and estrogen receptor-positive breast cancer in Hong Kong Chinese women. PLoS One. 2015;10(3), e0120741.

16. Li M, Tse LA, Chan WC, Kwok CH, Leung SL, Wu C, Yu WC, Yu IT, Yu CH, Wang $F$, et al. Evaluation of breast cancer risk associated with tea consumption by menopausal and estrogen receptor status among Chinese women in Hong Kong. Cancer Epidemiol. 2016:40:73-8.

17. Wacholder S, Silverman DT, McLaughlin JK, Mandel JS. Selection of controls in case-control studies. II. Types of controls. Am J Epidemiol. 1992;135(9):1029-41. 
18. Wacholder S, Rothman N, Caporaso N. Population stratification in epidemiologic studies of common genetic variants and cancer: quantification of bias. J Natl Cancer Inst. 2000;92(14):1151-8.

19. Block G, Hartman AM, Dresser CM, Carroll MD, Gannon J, Gardner L. A databased approach to diet questionnaire design and testing. Am J Epidemiol. 1986;124(3):453-69.

20. Arble DM, Bass J, Laposky AD, Vitaterna MH, Turek FW. Circadian timing of food intake contributes to weight gain. Obesity. 2009;17(11):2100-2.

21. Salgado-Delgado R, Angeles-Castellanos M, Saderi N, Buijs RM, Escobar C. Food intake during the normal activity phase prevents obesity and circadian desynchrony in a rat model of night work. Endocrinology. 2010;151(3):1019-29.

22. Andersen GS, Stunkard AJ, Sørensen TI, Petersen L, Heitmann BL. Night eating and weight change in middle-aged men and women. Int J Obes. 2004;28(10):1338-43.

23. Baron KG, Reid KJ, Kern AS, Zee PC. Role of sleep timing in caloric intake and BMI. Obesity. 2011;19(7):1374-81.

24. Eng S, Wagstaff DA, Kranz S. Eating late in the evening is associated with childhood obesity in some age groups but not in all children: the relationship between time of consumption and body weight status in US children. Int J Behav Nutr Phys Act. 2009;6(1):1.

25. Gallant A, Lundgren J, Drapeau V. The night-eating syndrome and obesity. Obes Rev. 2012;13(6):528-36.

26. Marinac CR, Nelson SH, Breen Cl, Hartman SJ, Natarajan L, Pierce JP, Flatt SW, Sears DD, Patterson RE. Prolonged nightly fasting and breast cancer prognosis. JAMA Oncol. 2016;2(8):1049-55.

27. Groen BB, Pennings B, Hertle E, Senden JM, Saris WH, van Loon LJ. Intragastric protein administration stimulates overnight muscle protein synthesis in elderly men. Am J Physiol Endocrinol Metab. 2012;302(1):E52-60

28. Waller SM, Vander Wal JS, Klurfeld DM, McBurney MI, Cho S, Bijlani S, Dhurandhar NV. Evening ready-to-eat cereal consumption contributes to weight management. J Am Coll Nutr. 2004;23(4):316-21.

29. Madzima TA, Panton LB, Fretti SK, Kinsey AW, Ormsbee MJ. Night-time consumption of protein or carbohydrate results in increased morning resting energy expenditure in active college-aged men. Br J Nutr. 2014; 111(01):71-7.

30. Kinsey AW, Eddy WR, Madzima TA, Panton LB, Arciero PJ, Kim J-S, Ormsbee MJ. Influence of night-time protein and carbohydrate intake on appetite and cardiometabolic risk in sedentary overweight and obese women. $\mathrm{Br}$ J Nutr. 2014;112(03):320-7

31. Ormsbee MJ, Kinsey AW, Eddy WR, Madzima TA, Arciero PJ, Figueroa A, Panton LB. The influence of nighttime feeding of carbohydrate or protein combined with exercise training on appetite and cardiometabolic risk in young obese women. Appl Physiol Nutr Metab. 2014;40(1):37-45.

32. Figueroa A, Wong A, Kinsey A, Kalfon R, Eddy W, Ormsbee MJ. Effects of milk proteins and combined exercise training on aortic hemodynamics and arterial stiffness in young obese women with high blood pressure. Am J Hypertens. 2014;27(3):338-44

33. Rose DP, Gracheck PJ, Vona-Davis L. The interactions of obesity, inflammation and insulin resistance in breast cancer. Cancers. 2015;7(4):2147-68.

34. Rose DP, Vona-Davis L. The cellular and molecular mechanisms by which insulin influences breast cancer risk and progression. Endocr Relat Cancer. 2012;19(6):R225-241.

35. Marinac CR, Sears DD, Natarajan L, Gallo LC, Breen Cl, Patterson RE. Frequency and circadian timing of eating may influence biomarkers of inflammation and insulin resistance associated with breast cancer risk. PLoS One. 2015;10(8), e0136240.

36. la Fleur SE, Kalsbeek A, Wortel J, Fekkes ML, Buijs RM. A daily rhythm in glucose tolerance: a role for the suprachiasmatic nucleus. Diabetes. 2001:50(6):1237-43.

37. Stokkan K-A, Yamazaki S, Tei H, Sakaki Y, Menaker M. Entrainment of the circadian clock in the liver by feeding. Science. 2001;291(5503):490-3.

38. Travis RC, Balkwill A, Fensom GK, Appleby PN, Reeves GK, Wang XS, Roddam AW, Gathani T, Peto R, Green J, et al. Night shift work and breast cancer incidence: three prospective studies and meta-analysis of published studies. J Natl Cancer Inst. 2016;108(12):djw169.

39. Pronk A, Ji BT, Shu XO, Xue S, Yang G, Li HL, Rothman N, Gao YT, Zheng W, Chow WH. Night-shift work and breast cancer risk in a cohort of Chinese women. Am J Epidemiol. 2010;171(9):953-9.
40. Li W, Ray RM, Thomas DB, Davis S, Yost M, Breslow N, Gao DL, Fitzgibbons ED, Camp JE, Wong E. Shift work and breast cancer among women textile workers in Shanghai. China Cancer Causes Control. 2015;26(1):143-50.

41. Blask DE. Melatonin, sleep disturbance and cancer risk. Sleep Med Rev. 2009:13(4):257-64

42. Altevogt BM, Colten HR. Sleep disorders and sleep deprivation: an unmet public health problem. Washington, D.C.: National Academies Press; 2006. p. 55-136.

43. McElroy JA, Newcomb PA, Titus-Ernstoff L, Trentham-Dietz A, Hampton JM, Egan KM. Duration of sleep and breast cancer risk in a large populationbased case-control study. J Sleep Res. 2006;15(3):241-9.

44. Kakizaki M, Kuriyama S, Sone T, Ohmori-Matsuda K, Hozawa A, Nakaya N, Fukudo S, Tsuji I. Sleep duration and the risk of breast cancer: the Ohsaki Cohort Study. Brit J Cancer. 2008;99(9):1502-5.

45. Wu AH, Wang RW, Koh WP, Stanczyk FZ, Lee HP, Yu MC. Sleep duration, melatonin and breast cancer among Chinese women in Singapore. Carcinogenesis. 2008;29(6):1244-8.

46. Pinheiro SP, Schernhammer ES, Tworoger SS, Michels KB. A prospective study on habitual duration of sleep and incidence of breast cancer in a large cohort of women. Cancer Res. 2006;66(10):5521-5.

47. Verkasalo PK, Lillberg K, Stevens RG, Hublin C, Partinen M, Koskenvuo M, Kaprio J. Sleep duration and breast cancer: a prospective cohort study. Cancer Res. 2005;65(20):9595-600.

48. Girschik J, Heyworth J, Fritschi L. Self-reported sleep duration, sleep quality, and breast cancer risk in a population-based case-control study. Am J Epidemiol. 2013;177(4):316-27.

49. Liang JA, Sun LM, Muo CH, Sung FC, Chang SN, Kao CH. Non-apnea sleep disorders will increase subsequent liver cancer risk - a nationwide population-based cohort study. Sleep Med. 2012;13(7):869-74.

50. Willett WC, Sampson L, Stampfer MJ, Rosner B, Bain C, Witschi J, Hennekens $\mathrm{CH}$, Speizer FE. Reproducibility and validity of a semiquantitative food frequency questionnaire. Am J Epidemiol. 1985;122(1):51-65.

51. Sharma S, Cade J, Jackson M, Mbanya J, Chungong S, Forrester T, Bennett F, Wilks R, Balkau B, Cruickshank JK. Development of food frequency questionnaires in three population samples of African origin from Cameroon, Jamaica and Caribbean migrants to the UK. Eur J Clin Nutr. 1996:50(7):479-86

52. Cade J, Thompson R, Burley V, Warm D. Development, validation and utilisation of food-frequency questionnaires-a review. Public Health Nutr. 2002:5(04):567-87.

\section{Submit your next manuscript to BioMed Central and we will help you at every step:}

- We accept pre-submission inquiries

- Our selector tool helps you to find the most relevant journal

- We provide round the clock customer support

- Convenient online submission

- Thorough peer review

- Inclusion in PubMed and all major indexing services

- Maximum visibility for your research

Submit your manuscript at www.biomedcentral.com/submit
) Biomed Central 